\title{
The Effectiveness of a Training Program based on Behaviorism in Improving the Skills of Motor Imitation in a Sample of Kids with Autism Spectrum Disorder in Jordan
}

\author{
Maisa' Isa Ahmed Al-Slaim \\ Prof. Essam Abdullah Al-Jdoua' \\ Department of Special Education \\ Faculty of Graduate Studies \\ The Word Islamic Science \& Education University \\ Amman- Jordan.
}

\begin{abstract}
This study aimed at detecting the effectiveness of a training program based on behaviorism to improve the skills of motor imitation in a sample of kids with autism spectrum disorder in Jordan. To achieve the aims of the study, two tools were applied in the study, prepared by the researcher, namely: (Motor Imitation Skills Scale, and Training Program). The study sample consisted of (20) children with autism spectrum disorders whom was enrolled in Al Tawasul Center for Autism in the capital, Amman, Jordan, aged 6-10 years, and they were divided equally into two groups: experimental and control. The study showed the following results: there are significant differences in motor imitation skills after the application of the program in favor of the experimental group. Also, there are significant differences in motor imitation skills of the experimental sample in favor of the post measurement. Finally, there are no significant differences in motor imitation skills between post measure of the experimental sample and trailing measurement.
\end{abstract}

Keywords: Autism Spectrum Disorder, Behaviorism, Motor Imitation Skills.

\section{Introduction}

Autism Spectrum Disorder (ASD) is an independent classifying category that has its own characteristics which distinguish it from other developmental disorders. It is characterized by its ambiguity and the strangeness of the resulting behavioral patterns; and it needs constant supervision and follow-up; also needs various programs, whether therapeutic or guidance or training. The origin of "Autism" is the orientation towards self, where the word (Autism) came from two Greek words, namely: (Aut) meaning self and (ism) meaning state; and the word is used to describe introverted person in abnormal shapes. In one way or another, children with ASD have difficulties developing and maintaining relationships with others; Difficulty communicating with parents or other children, forming relationships with others, and pretending to be play and imagination, dyslexia and dyspraxia(Terrell \& Passenger, 2013).

National Society of Autistic Children as cited in Yahya (2017) defined Autism as a basic diseases manifestation that appear before the child's age reaches (30) months; and includes disturbances in speed or succession of growth, sensory response to stimuli, speech, language and knowledge, and communication with people. While World Health Organization, WHO as cited in Al-Khatib (2018) viewed autism as World Health Organization, WHO as cited in Al-Khatib (2018) viewed autism as a neurodevelopment disorder that appears before the age of (3) years of the child's life, characterized by deficiencies in speech, language, cognitive ability, as well as communication.

However, Autism Spectrum Disorder (ASD) Is neurodevelopment behavioral disorder that appears before the age of three years of the child's life, characterized by deficiencies in speech, language, cognitive ability, an unusual response to sensory experiences, social interaction, repetitive behaviors and restricted interests; and closedmindedness, excessive thinking, impaired attention span, as well as a deficiency in verbal and non-verbal communication (Keenan \& Dillenburger, 2018; Ostergen, 2020). On the other hand, DSM-5 American Psychiatric Association, (2013) defined ASD as a severe psychological problem, including severe limitations in the child's cognitive, emotional and behavioral development; leads to limited and repetitive behaviors.

Data from Center for Disease Control and Prevention showed a significant increase in the rate of autism spectrum disorder, which reached about 1: 59, with an approximate increase of (0.02) of the number of children with special needs. Therefore, we must create solutions so our children can have meaningful lives as adult members of our community, so there has been an increase in interest in this disorder recently by specialists (Terman, 2020).

According to Losh et al., (2017) parents of children with Autism Spectrum Disorder (ASD) notice differences in their children's responses that involve biological movement, differences in brain activation during tasks, and in language processing and social communication, while 
Barbara \& Beta (2019) indicated the existence of many disorders closely related to autism spectrum disorder, which share the same basic features, but differ in specific symptoms, age of onset, or natural history, hence the agreement on the term "Autism spectrum disorder" as a more accurate and popular term.

In general, Children with ASD have main features, which are: sensory perception deficiency, repetitive and routine stereotypical behavior, short-ritual behaviors, deficits in joint attention, and the practice of some wrong and unwanted behaviors, such as: swinging and rotating movements, and abnormal responses to the senses, and the surrounding stimuli, and he does not seem interested in participating in activities or interests with others, and he usually prefers to play alone, shows exaggerated interest in a part of the thing more than the thing itself, and deficiencies in playing and imitation skills (Al-Zureikat, 2016; Al-Shami, 2004; Al-Zari, 2014 ; Qamish, 2015).

According to Strock (2007) children with ASD show less performance in imitation than normal children or children with other developmental disorders. The results of some studies confirmed a deficiency in the skill of imitation in children with ASD, and indicated the existence of a correlation between the deficiency of imitation skill and the deficit in their social communication behavior. In a more specific sense, imitation is related to the acquisition of social communication skills, as well as the development of social relationships, communication and skills that affect life-long learning (Charman, 2006; Vinanti \& Hamilton, 2014). Nadel (2006) emphasized that imitation has two functions: learning and social interaction. Imitation begins with noticing, and this is in the first twelve months of a child's life, followed by the expression of the first words. It is known that there is a vital relationship between imitation and language, as children begin to learn words as soon as the learning function is fulfilled, and they learn by observing others in their immediate environment.

Meanwhile Caroline \& Cathy (2012) pointed to a weakness in the motor imitation skills of most children with ASD, and emphasized that their movement disorders are clearly visible in activities that require precise, complex and overlapping movements or those that require ability in motor balance. Furthermore, Ming, Brimacombe \& Wagner (2007) believes that the decrease in movement disorders in adults with ASD is due to the processes of temporal development, training and treatment, or both, while Meghann, Megan \& Catherine (2013) described the differences between motor skills, and indicated that these skills increase with the age of the examinee.

And about the causes of ASD? (Here the question and investigation lies). Is it a neurological disease, or psychological, or caused by wounds or problems in the womb during childbirth, or the reason for the mother's rejection of her son, or because of a defect in the genes, or because of a lack of some minerals necessary for the body in food? Most of the studies and research, as well as the various explanations and the different causes of this disorder, have not confirmed one of them categorically, independently and explicitly about the underlying causes of autism spectrum disorder, and its issue remains confusing, and its causes remain as a puzzle (Abd, 2018). Mostly, children with ASD suffer from other disorders that accompany this disorder, such as, disorder in: (transition into adulthood and adolescence; attention deficit hyperactivity disorder; epilepsy; sleep; gastrointestinal tract; anxiety; depression) (Croen et al., 2015; Saadeh \& Al-Dahiri, 2018).

It was also found that behavioral therapy is one of the most popular treatment methods used with children of ASD, where behaviorism is based on the basis that behavior can be controlled by controlling the factors provoking it, and studying the environment in which it occurs (Smadi, 2020; Cooper, Heron \& Heward, 2007; Virues-Ortega, \& Yu, 2018).

where child with ASD suffers from deficiencies in the performance of many behavioral patterns that are practiced by normal children of their same age, at the age level between (5-10) years, this child cannot care for or protect himself (Dieringer, 2017). Therefore, working on developing and implementing training programs related to the skills of children with ASD, is a means for providing them with a new knowledge outcome that helps them learn alternative forms of communication (Ennis-Cole, Durodoye \& Harris, 2013; Ezell et al., 2012).

Due to the lack of local studies that have addressed training programs based on behaviorism to improve the skills of motor imitation for children with ASD. The researchers review studies related to imitation skills for children with ASD, in general, with different environments, according to various variables, and different age stages of this mysterious disorder, and those related to motor skills in particular; to benefit from their procedures and instruments building and arranged from newest to oldest.

Ruggeri et al., (2020) study within systematic review, examined the effect of motor and physical activity intervention on motor outcomes of children with ASD and the effect of motor learning strategies on motor skill acquisition, retention, and transfer. Six databases were searched from 2000 to 2019. Forty- one studies were included: 34 intervention studies and 7 motor learning studies, the overall quality of the evidence was low. Participants included 1173 children with ASD ranging from 3- 19 years, revealed that, more rigorous research on motor intervention is needed with well-controlled study designs, adequate sample sizes, and manualized protocols. In addition, research on motor learning strategies is warranted as it generalizes across motor interventions. 
Abed (2018) study about explain the behavioral symptoms of children with ASD in the light of the recent attitudes, the study conducted among 62 teachers of ASD children at West Bank, the most common behavioral symptoms of children with ASD were verbal communication disorders, the common behavioral symptoms was non-verbal communication disorders, the third common behavioral was assigned by four symptoms (imitation, adaptation to change, fear, nervousness, and body use). Results showed that a lack of interpretation of these behavioral characteristics leads to a decline in the level of services and treatment programs provided, moreover the study recommends enhancing the knowledge and skill of specialists in the behavioral characteristics of this disorder.

Al-Rawashda \& Olayyan (2016) study about the effectiveness of a behavioral training program to develop some fine motor skills for autistic children, the study sample consisted of (5) autistic children, whose ages ranged from (5-8) years, the results indicated that there are differences in the level of fine motor skills (basic hand skills, prewriting skills, and daily living skills) among the children of the experimental group and with whom the behavioral training program is used.

Similarly, Abu Hasaballah (2015) conducted a study to identify the effectiveness of a training program in developing nonverbal communication skills for mothers of autistic children at the Right to Live Association, the actual study sample consisted of 12 mothers who obtained the lowest marks on the communication scale Nonverbal gender, age groups, and educational stage were taken into consideration. the results indicate the effectiveness of the program in developing communication skills of mothers of autistic children. It was also found that there are no significant statistically significant differences between the post-measurement scores and the tracer measurement scores in the overall nonverbal communication score and its dimensions for mothers of children with autism, indicating the program's continued effectiveness.

Ali \& Al-Mellali (2013) study about the effectiveness of a training program for developing non-verbal behaviors among a sample of autism spectrum disorders (a quasi-experimental study in the Syrian Organization for the Disabled), the sample consisted of (8) children with ASD from the age group (4-8) years, a list was built to assess non-verbal behaviors consisting of (27) items distributed on four dimensions: (focus and attention, emotional expressions, communication and imitation, gestures and physical movements), the results showed the effectiveness of the training program in developing non-verbal behaviors in autistic children, to varying degrees, and most of them were the dimension of focus and attention and the least was $r$ gestures and physical movements.

Similarly, Oweijan (2012) conducted a study to identify the effectiveness of a training program in developing nonverbal communication skills in autism spectrum disorders, the study sample consisted of 20 children with autism, whose ages ranged between 3-6 years, the researcher prepared a list to estimate nonverbal communication skills, which were represented in (attention, imitation, eye contact, use of gestures, understanding some physical gestures, facial expressions and voice tones indicating them), the results indicated the effectiveness of the training program in developing nonverbal communication skills among autistic children.

Laine' (2010) study bout the slowing down the presentation of facial and body movement enhances imitation performance in children with autism, the study sample consisted of 9 children with autism, 37 typically-developing children and 17 children with Down syndrome, Imitation deficits observed among individuals with autism could be partly explained by the excessive speed of biological movements to be perceived and then reproduced, Also result showed that a subgroup of individuals with severe autism better reproduced the movements when presented slowly than at the ecological speed.

Finally, Beth, Sandra \& Brian (2009) study on the compare levels of gross motor and fine motor development in young children with ASD, and to compare their levels with children with developmental delay, 38 children with ASD, between 21 and 41 months of age, were assessed, the results showed that most of the children with ASD had generally similar levels of gross motor and fine motor development, Also the motor profiles of children with ASD were analogous to those of children with developmental delay.

Despite the benefit drawn by the researchers from previous studies regarding current study procedures, on motor imitation skills towards children with ASD in general, which was almost negative, but the researchers could not find study address training programs based on behavioral theory that serve this purpose. The study therefore sought to find out a training program based on behaviorism to improve the skills of motor imitation skills in a sample of children with ASD, aged 6- 10 years, in Al Tawasul Center for Autism in Amman- Jordan.

\subsection{Research Problem and Questions}

In response to the findings and recommendations of the previous researches and studies (Ruggeri et al., 2020), which recommended further studies on motor imitation skills in children with autism spectrum disorder; According to training programs based on behavioral theory; The little of local and Arab studies that dealt with this variable, the problem of the current study emerged from the importance of motor imitation of children with autism spectrum disorder (ASD). 
The current study therefore sought to detect "the effectiveness of a Training program based on behaviorism to improve the skills of motor imitation in a sample of kids with autism spectrum disorder in Jordan". Specifically, the current study seeks to answer the following questions:

a. Are there statistically significant differences between the experimental and control groups in motor imitation skills due to the training program?

b. Are there statistically significant differences between pre and post measurement in motor imitation skills of the experimental group?

c. Are there statistically significant differences between the post and trailing measurement (two weeks after the post measurement) after the end of the training program?

\subsection{Significance of the Research}

The significance of the study includes: The lack of local and Arab studies - within the limits of the researcher's knowledge - that dealt with motor imitation skills of children with Autism Spectrum Disorder (ASD) according to training programs based on behavioral theory; It is hoped that this study will develop a theoretical literature that is expected to be a reference for researchers in this field, in addition to knowing the effect of the training program in improving motor imitation skills; It is also hoped that this study will draw the attention of researchers to the importance of this topic, and re-shed light on this important group of children (ASD); it is also attempt to provide practical tools with appropriate psychometric properties that can be used by field workers and researchers as well ; Finally, the results of the current study may be provide recommendations and suggestions to strengthen the child with autism spectrum disorder (ASD) in which he can care for or protect himself.

\subsection{Operational Definitions of the Research}

Imitation Skills: One of the social communication skills that appears at an early stage of development, and plays a pivotal role in the growth of many cognitive skills and more complex skills, including skills of: objects imitation, motor imitation, imitation of gestures, and verbal imitation. Procedurally: it is the degree that the children with Autistic Spectrum Disorder (ASD) gets on the motor imitation skills scale prepared in the current study.

- Motor Imitation: It is the ability of a child with ASD to repeat physical movements using both the large movements and the delicate movements of the body, which the teacher or specialist ask him about (Ruggeri et al., 2020). Procedurally: It is the degree that the child with ASD gets on the motor imitation skills scale prepared by the researcher in the current study.

The Training Program: It is a program that is planned according to an organized scientific basis, to provide services to children with autism spectrum disorder, and includes a set of activities, educational experiences and learning styles on a topic or problem raised or discussed among a group of students under the supervision of the teacher. Procedurally: It is a set of structured procedures that were applied to students with autism spectrum disorder in the Autism Communication Center, using activities; To improve motor imitation skills and train them, according to a time plan that took more than a month, at a rate of (35) minutes over five sessions per week, by the teachers of (Al Tawasul Center for Autism), and under the supervision of the researcher.

\subsection{Limitations of the Research}

The study was confined to a sample of children with autism spectrum disorder, in the age group (6-10) years, in $\mathrm{Al}$ Tawasul Center for Autism, which specializes in caring for children with autism spectrum disorder in Amman Governorate, in the time period between (20/8/2020) until (20/9/2020) of the year 2019/2020. Also, the results of the research depend on the two tools used; therefore, the generalization of its results will be dependent on its validity and reliability indications.

\section{Methodology of the Research}

\subsection{Participants}

The study used judgmental/purposive sampling method which enabled the research to choose (20) children with autism spectrum disorders whom was enrolled in Al Tawasul Center for Autism in the capital, Amman, Jordan, aged 6- 10 years, and their cases were diagnosed through a set of tools approved by the center, so that it was taken into account that they do not have any other disabilities associated with autism spectrum disorder, with the help of specialists and teachers (trainers) present in the same center. and they were divided equally into two groups: experimental and control. 


\subsection{Instruments}

Depending on previous literature and studies related to training programs based on behaviorism in general, and motor imitation skills of kids with autism spectrum disorder in particular, a questionnaire measuring, and a training program were built, where researchers benefited from previous literature and modern studies on this subjects (Caroline \& Cathy, 2012; Beth, Sandra \& Brian, 2009; Escalona et al., 2002; Abed, 2018; Al-Rawashda \& Olayyan, 2016). The researchers reviewed published articles on different electronic sites related to motor imitations skills, and in light of the above, a scale (questionnaire) of 18 items to measure kids of ASD was formulated. Face validity of the instrument was assured by reviewing it by a group of experienced and efficient referees in various specialties (Special of Education, Measurement and Evaluation, Educational Psychology, Teaching Methods) and were asked to give their opinions in its items in terms of items clarity and language correctness, and items suitability in measuring the study purpose; and after this process (1) item was added.

The questionnaire consisted of 19 items in the final form, according to Likert scale (He can, He can to some extent, He can't, He can't absolutely). Had been taken into account in the formulation of items to be positive so that each given number $(4,3,2,1)$, respectively.

The instrument was administered on a sample of (25) kids of ASD from outside the study sample. It was applied twice with an interval of 10 days. Reliability was estimated by using Test- retest Method. Total reliability coefficient of the instrument was (0.89) which is considered acceptable for the purpose of the study.

In addition, a training program was built to improve motor imitation skills of children with Autism Spectrum Disorder (ASD), based on behavioral theory, through training sessions specially designed for this purpose.

The training program contains the following main points: (Activities and procedures that are applied in each training session separately; Behavior modification procedures for each training session; Enhancers, tools, methods, and techniques for improving the imitation of motor behaviors in every training session). and in light of the above, a training program of 21 sessions was formulated. Face validity of the instrument was assured by reviewing it by a group of experienced and efficient referees in various specialties (Special of Education, Measurement and Evaluation, Teaching Methods) and were asked to give their opinions in its items in terms of items clarity and language correctness, and items suitability in measuring the study purpose; and after this process some of the behavioral objectives related to the program have been reformulated. The final program consisted of 21 individual sessions.

The training program distributed as follows: an introductory individual session (a pre-measurement), and the motor imitation skills sessions with (19) sessions, in addition to one individual closing session (post measurement); Knowing that every session is (35) minutes every day for five days a week.

\subsection{Procedures}

Children with autism spectrum disorders in (Al Tawasul Center for Autism) were determined, and a meeting was held with them to explain the idea of motor imitation skills and the training program. Obtaining the official approval from the Word Islamic Science \& Education University in order to facilitate the researcher's mission. The researchers applied them the instruments of the study to get their response on each of the 19 items listed in the questionnaires.

\section{Results and Discussion}

3.1Are there statistically significant differences between the experimental and control groups in motor imitation skills due to the training program?. Mann Whitney Test for two independent samples (Mann-Whitney- U Test) to detect differences in imitation skills between the mean scores of the experimental and control groups responses were calculated in Table 3.1.

Table 3.1: Mann-Whitney- U Test of ASD responses on each experimental and control group pre- and post of applying the training program.

\begin{tabular}{llllllll}
\hline Variable & Group & $\mathrm{N}$ & $\begin{array}{l}\text { Sum of } \\
\text { Ranks }\end{array}$ & $\begin{array}{l}\text { Mean } \\
\text { Rank }\end{array}$ & $\begin{array}{l}\text { Mann- } \\
\text { Whitney- U }\end{array}$ & Z & Sig. \\
\hline Pre- & Experimental & 10 & 10.00 & 100.00 & 45.000 & -.379 & .705 \\
\hline Post & Control & 10 & 11.00 & 110.00 & & -2.689 & .007 \\
\hline
\end{tabular}

Table 3.1 shows that $\mathrm{z}$ score of responses after applying the training program was (-2.689), with sig. .007, which means that there were statistically significant differences at the level of significance $(\alpha=0.05)$ between the mean scores of children with autism spectrum disorder in the experimental and control groups, in motor imitation skills, 
in favor of children of the experimental sample, after applying the training program. The researcher believes that this result indicates that the procedures of the training program based on the behavioral theory, used in this study, had a positive impact on the improvement of motor imitation skills.

This might be due to the nature of the general and specific behavioral goals that were defined in the training program, the nature of the technical tools and methods used in implementing the training sessions for imitating motor skills, and the provision of the appropriate environment for their application, in addition to the evaluation methods used in each session. The reason may also be due to the modeling methods used in implementing the training program sessions. The training program takes into account the needs of the age group (6-10) years of children with autism spectrum disorder for the motor imitation skills that are most appropriate for them. Also, behavior modification methods used may be effective in the training program used in the current study, and the training of cooperating teachers on them was good. This finding is agreement with the results obtained by Ahmad (2009); Oweijan (2012);Laine et al., (2010); Ruggeri et al., (2020). These authors emphasized the effectiveness of training programs based on behavioral theory in improving imitation skills of children with autism spectrum disorder.

3.2 Are there statistically significant differences between pre and post measurement in motor imitation skills of the experimental group?. In answering this question, Wilcoxon test was used, and results are displayed in Table 3.2.

Table 4.2: Results of Wilcoxon test of the experimental group (10) children with ASD in the pre and post measurements, on the scale of motor imitation skills.

\begin{tabular}{|c|c|c|c|c|c|c|c|}
\hline Variable & & Ranks & $\mathrm{N}$ & Sum of Ranks & Mean Rank & $\mathrm{Z}$ & Sig. \\
\hline \multirow{4}{*}{$\begin{array}{l}\text { Motor } \\
\text { Skills }\end{array}$} & \multirow{4}{*}{ Imitation } & Negative & 0 & .00 & .00 & \multirow{4}{*}{-2.807} & \multirow{4}{*}{.005} \\
\hline & & Positive & 10 & 5.50 & 55.00 & & \\
\hline & & Ties & 0 & & & & \\
\hline & & Total & 10 & & & & \\
\hline
\end{tabular}

Table 3.2 shows that $\mathrm{z}$ score of responses after applying the training program was $(-2.807)$, with sig. .005, which means that there were statistically significant differences at the level of significance $(\alpha=0.05)$ between the mean ranks of the experimental group children in the pre and post measurements in motor imitation skills, in favor of the post measurement. This explains the effectiveness of the training program used in improving imitation motor skills of children with ASD. The researcher believes that training is the reason for this improvement, and the effectiveness of the techniques adopted by the researcher in implementing the training program sessions, and the tools used as well, were all meaningful and attractive to children with autism spectrum disorder.

This result may be attributed to the fact that all the motor skills mentioned in the scale are an essential part of the daily skills of the children with ASD and among their interest and desires. This finding supports what Ingersoll \& Meyer (2011) had indicated that there is a positive relationship between imitation, motor skills and the growth level of children with ASD.

This finding is inconsistent with Laine et al., (2010). The authors reported the weakness of children with ASD in motor imitation skills; on the other hand, this study is in agreement with the results obtained by Al-Rawashda \& Olayyan (2016); Ruggeri et al., (2020). This author emphasized the effect of imitation motor and physical skills on improving motor skills in children with ASD.

3.3 Are there statistically significant differences between the post and trailing measurement (two weeks after the post measurement) after the end of the training program?. In answering this question, Wilcoxon test was used, and Table 3.3 shows its results.

Table 3.3: Results of Wilcoxon test of the experimental group (10) children with ASD in the post and trailing measurements.

\begin{tabular}{lllllll}
\hline Variable & Ranks & $\mathrm{N}$ & Sum of Ranks & Mean Rank & Z & Sig. \\
\hline \multirow{5}{*}{ Trailing- Post } & Negative & 1 & 2.00 & 2.00 & & \\
& Positive & 2 & 2.00 & 4.00 & -.535 & .593 \\
& Ties & 7 & & & & \\
& Total & 10 & & & & \\
\hline
\end{tabular}

Table 3.3 shows no significant differences in motor imitation skills between post measure of the experimental sample and trailing measurement after two weeks of stopping the training program; This indicates the continuous improvement of children with ASD, and this is evidence of the effectiveness of the training program used in the current study in improving motor imitation skills of these children. And this might be due to the children benefiting from the program and the sessions that it is composed of, especially that it depended on what the child of ASD 
desires, and was built according to the needs of them and their daily skills. This finding is consistent with, Ahmad (2009); Oweijan (2012) results which showed there are statistically significant differences between post measure of the experimental sample and trailing measurement, in favor of the training program.

\subsection{Recommendations}

Based on the findings of the current study, the researchers recommend the following:

1. The need to adopt the training program prepared in the current research and applying in children of autism spectrum disorder in various special education centers and institutions; Due to its effectiveness in improving the imitation skills of this group of children.

2. It is important that Ministry of Education in Jordan makes to conduct special sessions, workshops, and conferences to educate caregivers of children with autism spectrum disorder on how to train them in motor imitation skills, and include them in guides that can be guided.

3. More similar studies be conducted on the effect of training programs based on behaviorism to improve the skills of motor imitation in a sample of kids with autism spectrum disorder in Jordan, while including other age groups and other imitation skills, like verbal imitation, as well as expanding the research scope to include other areas of (ASD).

\section{References}

Abed, M. (2018). Explaining the behavioral characteristics of the children with Autism Spectrum Disorder according to the modern diagnostic criteria (DSM-V). Dirasat, Educational Sciences, 45 (3), 345-359.

Abu Hasaballah, O. (2015). The effectiveness of a training program in developing communication skills of children with autism mothers. Unpublished MA Thesis, Islamic University, Gaza, Palestine.

Ahmad, F. (2009). The effectiveness of a behavioral program in developing some emotional expressions among a sample of autistic children. research presented at the Damascus University Conference (Towards a Better Investment in Psychological Sciences) held during the period between 25-27 / 10/2009.

Al Hisan, M. (2014). The First Guide for Autism Programs $\left(3^{\text {rd }}\right.$ ed.). Riyadh: King Fahd National Library for Publishing and Distribution.

Ali, D., \& Al-Mellali, S. (2013). The effectiveness of a training program for developing non-verbal behaviors among a sample of autism spectrum disorders (a quasi-experimental study in the Syrian Organization for the Disabled). Journal of Damascus University, 29 (1), 193-234.

Al-Khatib, J., Al-Samadi, J., Al-Rousan, F., Al-Hadidi, M., Yahya, K., Al-Natour, M., Al-Zureikat, I., AlAmaiyrah, M., \& Al-Sorour, N. (2018). Introduction to the education of students with special needs ( $7^{\text {th }}$ ed.). Amman: Dar Al Fikr for Publishing and Distribution.

Al-Qamish, M. (2015). Autism Disorders: Causes, Diagnosis, Treatment, Scientific Studies (2 ${ }^{\text {nd }}$ ed.). Amman: Dar AlMaseerah for Publishing and Distribution.

Al-Rawashda, M., \& Olayyan, H. (2016). The effectiveness of a behavioral training program to develop some fine motor skills in autistic children. Journal of Educational Sciences, 2, 147-184.

Al-Shami, W. (2004). Characteristics of autism, its development and how to deal with it. Saudi Arabia, Riyadh: Fahd National Library.

Al-Zari', N. (2014). Introduction to autism spectrum: basic concepts and intervention methods. Amman: Dar AlFikr for Printing and Publishing.

Al-Zureikat, I. (2016). Autism, behavior, diagnosis, and treatment( $2^{\text {nd }}$ ed.). Jordan, Amman: Dar Wael for Publishing and Distribution.

American Psychiatric Association. (2013). Diagnostic and statistical manual of mental disorders, (DSM-5) (5 ${ }^{\text {th }}$ ed.). Arlington, Texas: American Psychiatric Publishing, Crossref.

Barbara, K., \& Beta, N. (2019). Genetics and epigenetics of autism spectrum disorder-current evidence in the field. Journal of Applied Genetics, 60, 37- 47.

Beth, P., Sandra, H., \& Brian, R. (2009). Lopez levels of gross and fine motor development in young children with autism spectrum disorder. Physical \& Occupational Therapy In Pediatrics, 27(3), 21- 36.

Caroline, S., \& Cathy, A. (2012). Teaching imitation to children with autism: A focus on social reciprocity. The Journal of Speech and Language Pathology, Applied Behavior Analysis, 2(3), 269- 277.

Charman, T. (2006). Imitation and the development of language. New York: The Guilford Press.

Cooper, J., Heron, T., \& Heward, W. (2007). Applied behavior analysis. New Jersey: Pearson Education.

Croen, L., Zerbo, O., Qian, Y., Massolo, M., Rich, S., Sidney, S., \& Kripke, C. (2015). The health status of adults on the autism spectrum. National Autistic Society, 19(7), 320- 327.

Dieringer, S., Zoder, K., Porretta, L., Bricker, A., \& Ricks, K. (2017). Increasing physical activity in children with autism through music, prompting and modeling. Psychology in the Schools, 54(4), 421- 432.

Ennis-Cole, D., Durodoye, B., \& Harris, H. (2013). The impact of culture on autism diagnosis and treatment: Considerations for counselors and other professionals. The Family Journal, 21(3), 279- 287. 
Escalona, A., Field, T., Nadel, J., \& Lundy, B. (2002). Brief report: Imitation effects on children with autism. Journal of Autism and Developmental Disorders, 23(2), 10-14.

Ezell, S., Field, T., Nadel, J., Newton, R., Murrey, G., Siddalingappa, V., \& Grace, A. (2012). Imitation effect on joint attention behaviors of children with autism. Psychology, 3(9), 681- 686.

Keenan, M., \& Dillenburger, K. (2018). How fake news affects autism policy. Societies, 8(2), 29- 40.

Laine', F., Rauzy, S., Tardif, C., Gender, B. (2010). Slowing down the presentation of facial and body movement enhances imitation performance in children with autism. Journal of Autism and Developmental Disorders, 41(8), 982- 997.

Losh, M., Martin, G., Lee, M., Klusek, J., Sideris, J., Barron, S., \& Wassink, T. (2017). Developmental markers of genetic liability to autism in parents: A longitudinal, multigenerational study. Journal of Autism Development Disorders, 47(3), 834- 845.

Meghann, L., Megan, M., \& Catherine, L. (2013). Motor skills of toddlers with autism spectrum disorders. Journal of Autism and Developmental Disorders, 17(2), 133- 146.

Ming, X., Brimacombe, M., \& Wagner, G. (2007). Prevalence of motor impairment in autism spectrum disorders. Brain Development Journal, 29(9), 565- 573.

Nadel, J. (2006). Does Imitation matter to children with autism?In S. New York: The Guilford Press.

Nunally, J. (1982). Psychometric Theory(1 ${ }^{\text {st }}$ ed.). New York: McGraw Hill Book Company.

Ostergen, J. (2020). Speech-Language Pathology Assistants: A Resource Manual (1st Ed.) [Online]. Chapter 17, Autism Spectrom Disorders (ASD). Available: ISBN13: 978-1-94488-326-3.

Oweijan, B. (2012). The effectiveness of a training program in developing nonverbal communication skills in autism spectrum disorders. Unpublished MA thesis, University of Damascus, Syria.

Ruggeri, A., Dancel, A., Johnson, R., \& Sargent, B. (2020). The effect of motor and physical activity intervention on motor outcomes of children with autism spectrum disorder: A systematic review. Autism Spectrum Disorder, 24(3), 544- 568.

Saadeh, H., \& Al-Dahiri, S. (2018). The effectiveness of counseling program in view of behavior theory in reducing the psychological stress and depression among mothers of autistic children in the kingdom of Saudi Arabia. PhD dissertation, The Word Islamic Science \& Education University, Amman, Jordan.

Smadi, S. (2020). Parental beliefs and feeling about autism spectrum disorder in Iran. International Journal of Environmental Research and Public Health, 17, 1- 15.

Strock, M. (2007). Autism spectrum disorder (Pervasive Developmental Disorder). National Institute of Mental Health (NIH), 4, 1- 41.

Terman, D. (2020). The superpowers of children on the autism Spectrum. OC Leader Board, Opinion, Analysis, Insight, 51- 59.

Terrell, Colin ., \& Passenger, Terry. (2013). ADHD Autism, Dyslexia and Dyspraxia (Understanding)(translation by Marc Abboud). Riyadh: King Fahd National Library.

Vinanti, G., \& Hamilton, A. (2014). Imitation in autism spectrum disorders. Hoboken, NJ: Wiley.

Virues-Ortega, J., \& Yu, C. (2018). The process of knowledge translation in behavior analysis. Operant, 1, 8- 9.

Yahya, K. (2017). Educational programs for persons with special needs ( $1^{\text {st }} \mathrm{ed}$.). Amman: Dar Al Maseerah for Publishing and Distribution. 